\title{
Delay in hepatocyte proliferation and prostaglandin D2 synthase expression for cholestasis due to endotoxin during partial hepatectomy in rats
}

\author{
YUSUKE WAKASA $^{1}$, NORIHISA KIMURA ${ }^{1}$, TOSHIYUKI YAMADA ${ }^{2}$, \\ TAKESHI SHIMIZU ${ }^{2}$, KENICHI HAKAMADA ${ }^{1}$ and SHIGEKI TSUCHIDA ${ }^{2,3}$ \\ Departments of ${ }^{1}$ Gastroenterological Surgery and ${ }^{2}$ Biochemistry and Genome Biology, \\ Hirosaki University Graduate School of Medicine, Hirosaki, Aomori 036-8562; \\ ${ }^{3}$ Department of Rehabilitation Sciences, Hirosaki University of Health and Welfare, Hirosaki, Aomori 036-8102, Japan
}

Received February 19, 2019; Accepted August 22, 2019

DOI: $10.3892 / \mathrm{mmr} .2019 .10681$

\begin{abstract}
Infection is a frequent complication of liver transplantation or partial hepatectomy $(\mathrm{PH})$ and sometimes results in cholestasis. We examined factors involved in infection-induced cholestasis after $\mathrm{PH}$, employing a rat $\mathrm{PH}$ model and lipopolysaccharide (LPS) as a bacterial toxin. Male Sprague-Dawley rats were subjected to $70 \% \mathrm{PH}$ and/or LPS injection, and tissues were harvested at $0,24,72$ and $168 \mathrm{~h}$. Gene expression was analyzed by microarray analysis and reverse transcription-quantitative polymerase chain reaction, and protein levels and localization were analyzed by western blotting and immunohistochemistry, respectively. Plasma bile acid levels were significantly higher in the LPS + PH group than in the PH group. Ribonucleotide reductase regulatory subunit M2 and proliferating cell nuclear antigen peaked at 24 and $72 \mathrm{~h}$ in the PH group and LPS + PH group, respectively, indicating a delay in cell proliferation in the latter group. The sodium-dependent taurocholate cotransporting polypeptide and organic-anion-transporting polypeptide 1a1 and 1a2 were reduced in the $\mathrm{PH}$ group at $24 \mathrm{~h}$, and were not further decreased in the LPS + PH group. Chemokine ligand 9 (Cxcl9), a chemokine involved in M2 macrophage polarization, increased after $24 \mathrm{~h}$ in the LPS and the LPS + PH groups. The number and shape of Cxc19-positive cells were similar to CD163-positive cells, suggesting that such cells produced the chemokine. Hematopoietic prostaglandin $\mathrm{D}_{2}$ synthase (Ptgds2) was only detected in hepatocytes of the LPS + PH group exhibiting a delay in cell proliferation. Thus, Kupffer cells activated with
\end{abstract}

Correspondence to: Professor Shigeki Tsuchida, Department of Rehabilitation Sciences, Hirosaki University of Health and Welfare, 3-18-1 Sanpinai, Hirosaki, Aomori 036-8102, Japan

E-mail: tsuchidas@jyoto-gakuen.ac.jp

Key words: cholestasis, partial hepatectomy, lipopolysaccharide, $\mathrm{ABC}$ transporter, liver regeneration, Kupffer cell, chemokine
LPS were suggested to be responsible for a delay in hepatocyte proliferation after $\mathrm{PH}$.

\section{Introduction}

The liver is a unique organ with the capacity to regenerate following the removal of two-thirds of liver mass (1). Liver regeneration requires the precisely coordinated proliferation of the two major hepatic cell populations, hepatocytes and liver sinusoidal endothelial cells to reconstitute liver structure and function (2). Liver regeneration also requires the interaction between hepatocytes and other component cells, such as Kupffer cells and hepatic stellate cells $(1,3,4)$. Numerous molecules, including hepatocyte growth factor and epidermal growth factor have been demonstrated as mitogens produced in nonparenchymal cells (5). Suppressed liver regeneration is of major concern for small remnant liver volume in adult living donor transplantation or in bacterial infection after partial hepatectomy ( $\mathrm{PH})$, as this has been associated with cholestasis and mortality (6).

Hepatocytes under physiological conditions efficiently extract bile acids from sinusoids via the sodium-dependent taurocholate cotransporting polypeptide (Ntcp) and the sodium-independent organic anion transporting polypeptide (Oatp1) (7). The extracted bile acids are excreted into the bile canaliculi by ATP-dependent transporters, such as the bile salt export pump (7). In our previous study, 90\% PH in rats resulted in high blood bile acids levels and the suppression of Ntcp expression (6). Thus, lower uptake of bile acids has been suggested to be partly involved in cholestasis (6).

Infection is a frequent complication after living donor liver transplantation (8). Low-dose lipopolysaccharide (LPS) application after PH in mice was reported to delay liver proliferation (9). As LPS is known to activate Kupffer cells (10), this suggests that activated Kupffer cells may inhibit liver proliferation; however, it has been demonstrated that Kupfer cells stimulate liver regeneration after PH (1); depletion of Kupffer cells by clodronate delays liver regeneration (11). Therefore, Kupffer cells activated by LPS may lose their capacity to induce hepatocyte proliferation after PH. 
The present study examined whether LPS-induced cholestasis is also due to the suppression of Ntcp expression, as observed in $90 \% \mathrm{PH}$ rats. It also examined whether Kupffer cells activated by LPS inhibit or stimulate liver regeneration after PH. The expression of anion transporters for the uptake from the sinusoid was decreased in PH, but LPS did not further decrease their expression. This suggested that decreases in these transporters were not responsible, but a delay in hepatocyte proliferation may be linked to LPS-induced cholestasis. LPS treatment alone or in combination with $\mathrm{PH}$ induced Kupffer cell activation with a CD163-positive phenotype, a marker for M2-type macrophages (12); CD163-positive cells were suggested to produce chemokine ligand 9 ( $\mathrm{Cxc19}$ ), which was determined to be involved in chronic inflammation (13) and M2 macrophage polarization (14). As hematopoietic type prostaglandin D2 synthetase (Ptgds2) is known to inhibit lymphocyte proliferation (15), Ptgds 2 staining was performed. Hepatocytes in the LPS + PH group were stained and markedly stained at $24 \mathrm{~h}$, a time point when cell proliferation was notably inhibited. On the contrary, hepatocytes in the LPS or the $\mathrm{PH}$ groups were not stained.

\section{Materials and methods}

Animals and animal treatment. Male Sprague-Dawley rats weighing 180-220 g and 6 weeks old were purchased from Charles River Laboratories Japan, Inc. In total 39 rats were used and they were housed under routine laboratory conditions at the animal laboratory of Hirosaki University. The rats received standard laboratory chow, had free access to food and water, and were kept in a thermostatically controlled room $\left(25^{\circ} \mathrm{C}\right)$ with a 12 -h light-dark cycle. Before undergoing surgical procedures, all rats were fasted for $24 \mathrm{~h}$. The rats were divided into five groups: Control group without any treatment, sham group receiving laparotomy alone, LPS group receiving intravenous LPS $75 \mu \mathrm{g} / \mathrm{rat}, \mathrm{PH}$ group receiving $70 \% \mathrm{PH}$, and $\mathrm{LPS}+\mathrm{PH}$ group receiving intravenous LPS injection immediately after $\mathrm{PH}$. 70\% $\mathrm{PH}$ was performed as reported previously (6). The rats of four groups except the control group were sacrificed at 24, 72 and $168 \mathrm{~h}$ after laparotomy or PH and/or LPS treatment. Those of the control group were sacrificed at $0 \mathrm{~h}$. Three rats each were used at respective time points of each group. LPS (O55:B5, L2880) was purchased from Sigma-Aldrich (Merck KGaA). After the surgical procedures, the rats had free access to a $200 \mathrm{~g} / 1$ glucose solution for $24 \mathrm{~h}$ to avoid post-operative hypoglycemia after hepatectomy. The present study was performed in accordance with the Guidelines for Animal Experimentation, Hirosaki University, and all of the animals received humane care according to the criteria outlined in the 'Guide For The Care And Use Of Laboratory Animals' prepared by the National Academy of Sciences and published by the National Institutes of Health (16).

Plasma total bilirubin and bile acids. Blood from the hearts was collected in test tubes containing EDTA and plasma was prepared after centrifugation at 2,500 x g, for $10 \mathrm{~min}$ at room temperature. Plasma total bilirubin, aspartate aminotransferase (AST), and alanine aminotransferase (ALT) were measured using Spotchem EZ (ARKRAY, Inc.) with SPOTCHEM
II Basic Panel 2 Test Strips (MT-7785; ARKRAY, Inc.), according to the manufacturer's protocols. The plasma levels of total bile acids were measured with an assay kit (Diazyme Laboratories), according to the manufacturer's protocol.

Microarray analysis. Total RNA was extracted from frozen liver samples at $0,24,72$ and $168 \mathrm{~h}$ after $70 \%$ hepatectomy and/or LPS injection with TRIzol ${ }^{\circledR}$ reagent (Thermo Fisher Scientific, Inc.). Equal amounts of RNA from three individual livers were combined, and $10 \mu \mathrm{g}$ of RNA was used to produce biotin-labeled complementary RNA (cRNA) with GeneChip IVT labeling kit (Affymetrix; Thermo Fisher Scientific, Inc.). The labeled and fragmented cRNA was subsequently hybridized to GeneChip ${ }^{\circledR}$ Rat Gene-ST 2.0 Array (Affymetrix; Thermo Fisher Scientific, Inc.). Labeling, hybridization, image scanning and data analysis were performed at TOHOKU CHEMICAL Co., Ltd.

Reverse transcription-quantitative polymerase chain reaction (RT-qPCR). Complementary DNA (cDNA) was reverse-transcribed from $1 \mu \mathrm{g}$ of total RNA using the Omniscript RT kit (Qiagen, Inc.), according to the manufacturer's protocols. A MiniOpticon Detection System (Bio-Rad Laboratories, Inc.) and SYBR ${ }^{\circledR}$ Green Supermix (Bio-Rad Laboratories, Inc.) were used for the quantitation of specific mRNA. The amplification of ubiquitin $C$ cDNA was performed to standardize the levels of the target cDNA, as reported previously (6). Gene-specific primers were designed according to known rat sequences (Table I). PCR amplification consisted of $30 \mathrm{sec}$ at $94^{\circ} \mathrm{C}, 30 \mathrm{sec}$ at $55-60^{\circ} \mathrm{C}$ and $30 \mathrm{sec}$ at $72^{\circ} \mathrm{C}$ for $30-35$ cycles. No non-specific $\mathrm{PCR}$ products, as detected by melting temperature curves, were found. After normalizing the expression of the target gene to ubiquitin $C$ expression using the $2^{-\Delta \Delta C t}$ method reported by Livak and Schmittgen (17) in triplicate; the levels of mRNA expression in three samples at respective time points $(0,24,72$, and $168 \mathrm{~h}$ after treatment) were expressed relative to the control values.

Western blotting. Crude liver membranes were prepared according to the method of Gant et al (18) and the samples (100 $\mu \mathrm{g}$ protein each) were dissolved in sample buffer and separated via $7.5 \%$ SDS-PAGE with a $4.4 \%$ stacking gel. Protein content was measured by Bradford's method (19) using a bovine serum albumin standard curve. Following electrophoresis, the proteins were transferred to polyvinylidene fluoride membranes (Hybond-P, GE Healthcare). After blocking with $4 \%$ nonfat dry milk in Tris-buffered saline for $2 \mathrm{~h}$ at room temperature, membranes were incubated overnight at $4^{\circ} \mathrm{C}$ with primary anti-Ntcp antibody (sc-107029; 1:10,000, Santa Cruz Biotechnology, Inc.) or anti- $\beta$-actin antibody (ab227387; 1:1,000, Abcam). Immune complexes were detected using a horseradish peroxidase conjugated anti-rabbit $\operatorname{IgG}$ secondary antibody (NA934; 1:2,000, GE Healthcare) and visualized with an enhanced chemiluminescent kit (ECL Plus; GE Healthcare).

Immunostaining. Liver tissue samples were fixed in $10 \%$ neutral buffered formaldehyde for two days at $4^{\circ} \mathrm{C}$ and embedded in paraffin. These paraffin blocks were sliced into $4 \mu \mathrm{m}$ sections and passed through xylene and a graded alcohol series. The 
Table I. Reverse transcription-quantitative polymerase chain reaction primer sequences.

\begin{tabular}{|c|c|c|}
\hline Gene & Forward primer $\left(5^{\prime} \rightarrow 3^{\prime}\right)$ & Reverse primer $\left(5^{\prime} \rightarrow 3^{\prime}\right)$ \\
\hline$A b c c 2$ & CACAGGTTTGCCCATTATCC & ATATTGAGGGCGTTGGACAG \\
\hline Slcloal & AGGCATGATCATCACCTTCC & AAGTGGCCCAATGACTTCAG \\
\hline Slc21al & TACATGTCAGCTTGCCTTGC & GCGGGAATACCAGCAAATAC \\
\hline Slc21a2 & CAATTCGGTATCCCCACATC & GTTTGAGGACACGTTGCTTG \\
\hline Rrm2 & GCACTGGGAAGCTCTGAAAC & GGCAATTTGGAAGCCATAGA \\
\hline Pcna & GGTGAAGTTTTCTGCGAGTG & CTCAGAAGCGATCGTCAAAG \\
\hline Cxcl9 & TCGAGGAACCCTAGTGATAAGGAATCAG & TTTGCTTTTTCTTTTGGCTGATCTTTTTC \\
\hline
\end{tabular}

Abcc2, ATP binding cassette subfamily C member 2; Slc10a1, sodium-dependent taurocholate cotransporting polypeptide; Slc21a1, solute carrier organic anion transporter 1a1; Slc21a2, solute carrier organic anion transporters 1a2; Rrm2, ribonucleotide reductase regulatory subunit M2; Pcna, proliferating cell nuclear antigen; Cxc19, chemokine ligand 9.
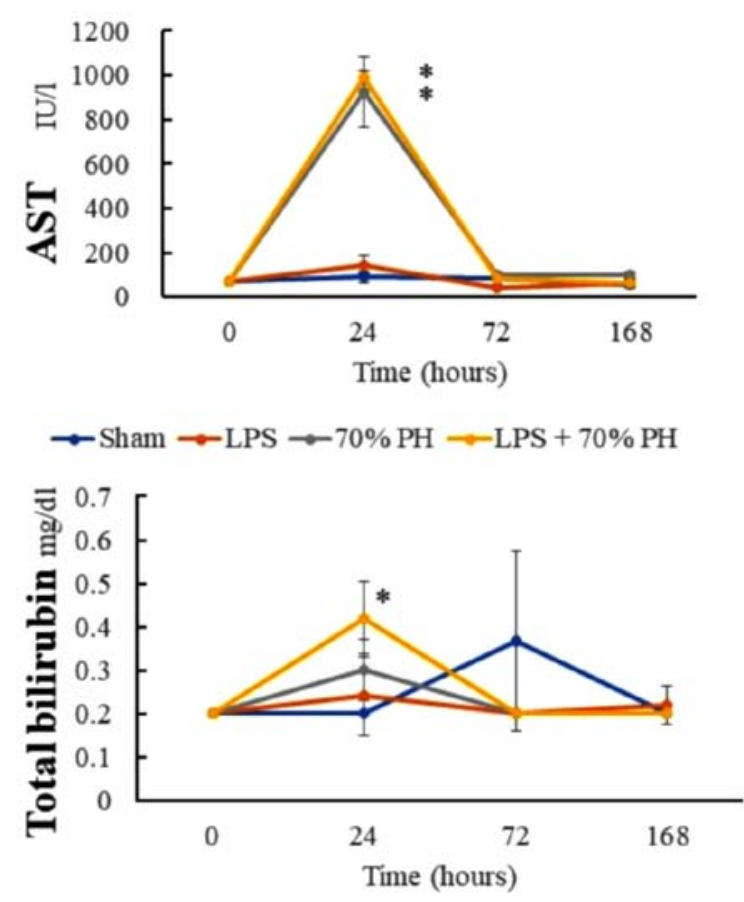

$\rightarrow$ sham $\rightarrow$ LPS $\rightarrow 70 \% \mathrm{PH} \rightarrow \mathrm{LPS}+70 \% \mathrm{PH}$
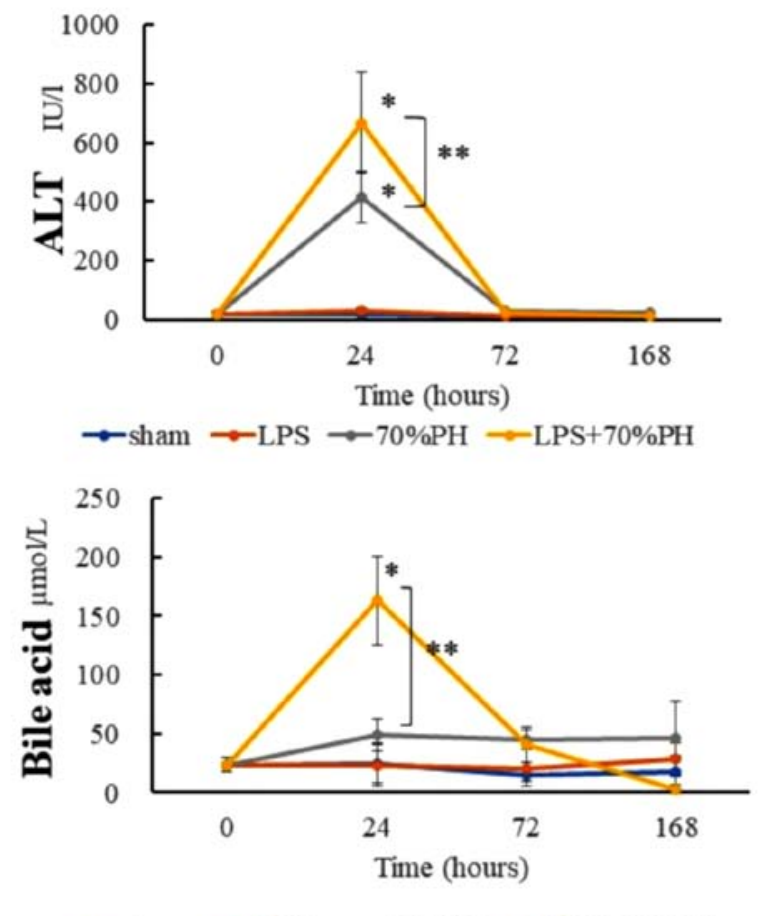

$\rightarrow$ sham $\rightarrow$ LPS $\rightarrow 70 \% \mathrm{PH} \rightarrow$ LPS $+70 \% \mathrm{PH}$

${ }^{*} p<0.05$ vs. sham group; ${ }^{* *} p<0.05$ LPS $+70 \%$ PH group vs. $70 \% \mathrm{PH}$ group.

Figure 1. Levels of plasma AST, ALT, total bilirubin and bile acids at 0 (control), 24, 72, and $168 \mathrm{~h}$ after a sham operation (blue), LPS administration (orange), $70 \% \mathrm{PH}$ (gray), and LPS $+70 \% \mathrm{PH}$ (yellow). The biomarker levels were quantified with a commercial kit. Data are presented as the mean \pm standard deviation from three rats. ${ }^{*} \mathrm{P}<0.05$ vs. sham group; ${ }^{* *} \mathrm{P}<0.05 \mathrm{LPS}+70 \% \mathrm{PH}$ group vs. $70 \% \mathrm{PH}$ group. ALT, alanine aminotransferase; AST, aspartate aminotransferase; LPS, lipopolysaccharide; PH, partial hepatectomy.

deparaffinized sections were stained with hematoxylin solution at room temperature for 5 min. Following washing with water and passing through a graded alcohol series, the sections were stained with eosin solution for $1 \mathrm{~min}$. The deparaffinized sections were also stained for CD68, CD163, Cxc19, and Ptgds2 using a standard avidin-biotin-peroxidase conjugate method (20) using an automated immunostaining instrument (Benchmark XT; Ventana Medical System). The slides were blocked with $0.3 \%$ hydrogen peroxide and then incubated for $1 \mathrm{~h}$ at room temperature with the primary antibodies. The antibodies employed were: Anti-CD68 antibody (MCA 341R; 1:100, Bio-Rad Laboratories, Inc.), anti-CD 163 antibody (sc-58965; 1:500, Santa Cruz Biotechnology, Inc.), anti-Cxc19 antibody (bs-2551R; 1:500, BIOSS Inc.), and anti-Ptgds2 antibody (PA 5-43217; 1:500, Invitrogen; Thermo Fisher Scientific, Inc.). Non-immune $\gamma$-globulin fractionated from rabbit sera by $20-40 \%$ saturation of ammonium sulfate (21) was used as a negative control instead of primary antibody. The biotinylated anti-rabbit IgG or anti-mouse $\operatorname{IgG}$ antibodies and Vectastain ABC kit (PK6101) were obtained from Vector 


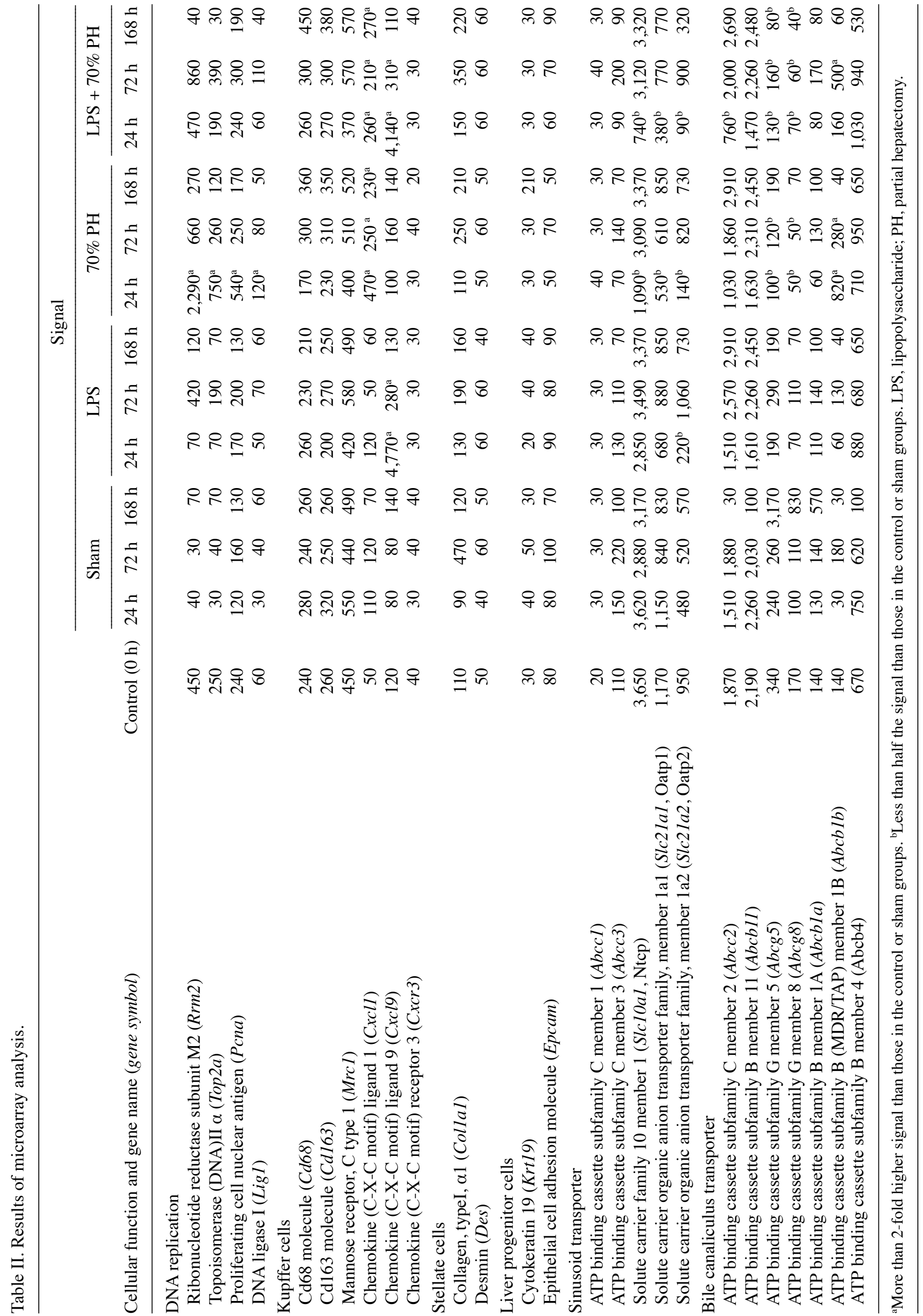



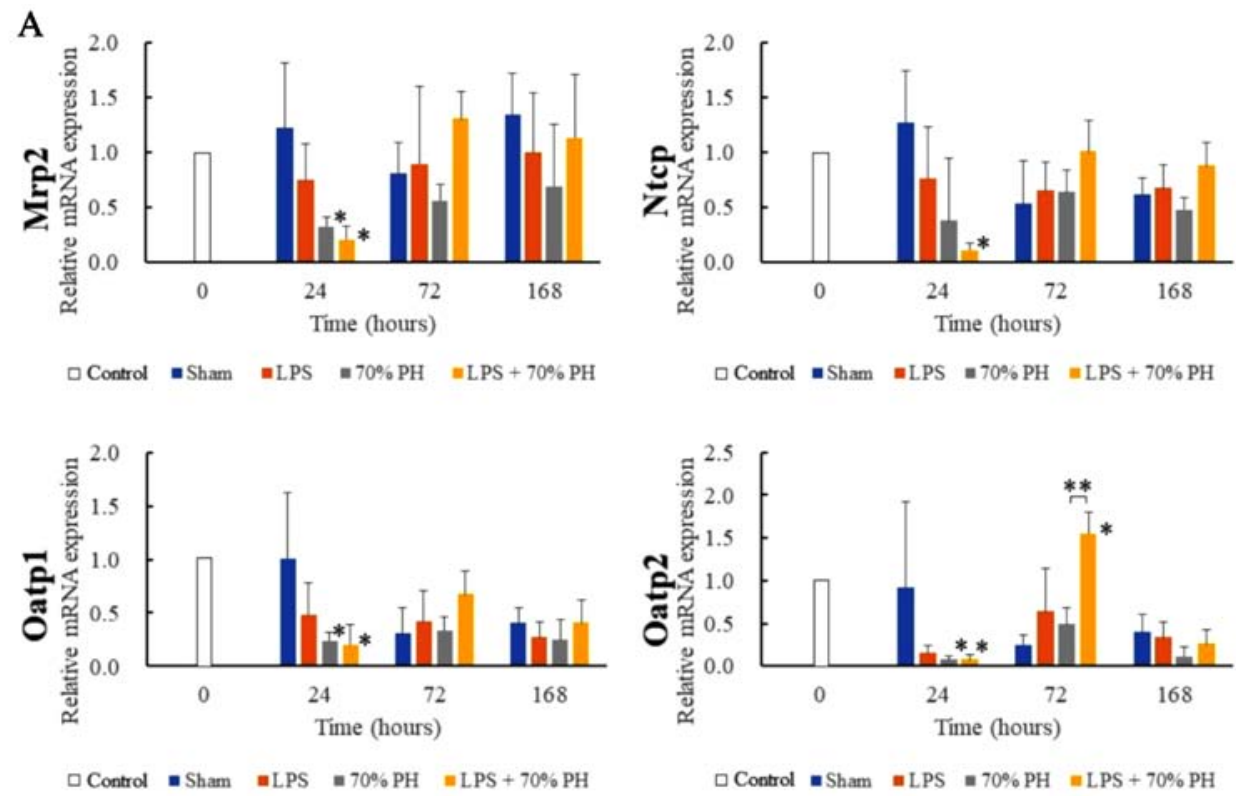

${ }^{*} p<0.05$ vs. sham group; ${ }^{* *} p<0.05$ LPS $+70 \%$ PH group vs. $70 \% \mathrm{PH}$ group.

B
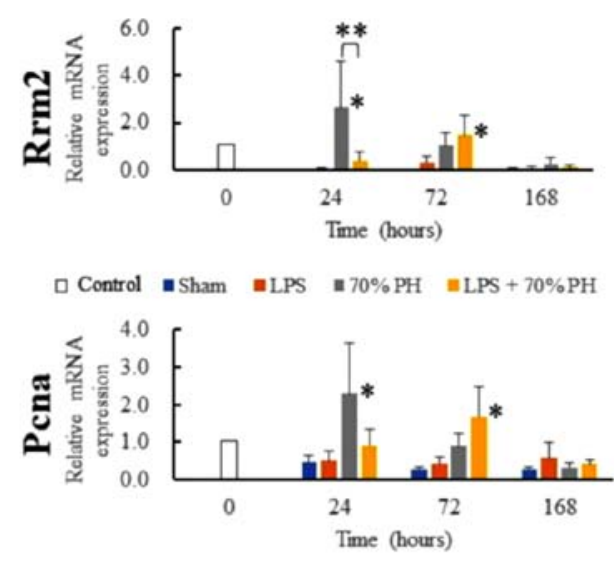

$\square$ Control $=$ Sham $=$ LPS $=70 \% \mathrm{PH}=\mathrm{LPS}+70 \% \mathrm{PH}$

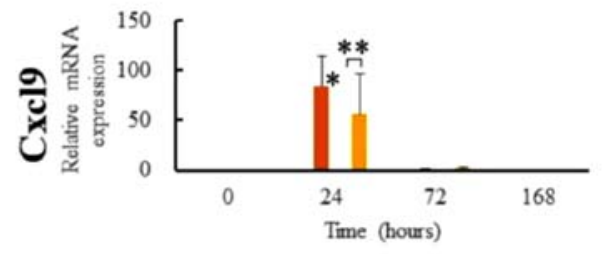

$\square$ Control $=$ Sham $=$ LPS $=70 \% \mathrm{PH} \equiv \mathrm{LPS}+70 \% \mathrm{PH}$

$" p<0.05$ vs. sham group; $" * p<0.05$ LPS $+70 \%$ PH group vs. $70 \%$ PH group.

Figure 2. Quantitation of mRNA expression. The expression of (A) organic anion transporters, and (B) DNA replication genes and Cxc19 at 0,24,72, and $168 \mathrm{~h}$ after the sham operation (blue), LPS administration (orange), PH (gray), and LPS + PH (yellow). The quantification of Mrp2, Ntcp, Oatp1, Oatp2, Rrm2, Pcna and $\mathrm{Cxcl} 19 \mathrm{mRNA}$ expression was conducted via reverse transcription-quantitative polymerase chain reaction. The mRNA expression levels at 24,72 and $168 \mathrm{~h}$ are expressed relative to the values of individual mRNA at $0 \mathrm{~h}$. Data are presented as the mean \pm standard deviation from three rats. " $\mathrm{P}<0.05 \mathrm{vs}$. sham group; ${ }^{* *} \mathrm{P}<0.05$ LPS $+70 \%$ PH group vs. 70\% PH group. Mrp2, ATP binding cassette subfamily C member 2; Ntcp, taurocholate cotransporting polypeptide; Oatp1, solute carrier organic anion transporters 1a1; Oatp2, solute carrier organic anion transporters 1a2; Rrm2, ribonucleotide reductase regulatory subunit M2; Pcna, proliferating cell nuclear antigen; Cxcl9, chemokine ligand 9; LPS, lipopolysaccharide; PH, partial hepatectomy.

Laboratories, Inc. The specific binding was visualized with a 3,3'-diaminobenzidine tetrahydrochloride solution. Sections were then lightly counterstained with hematoxylin for microscopic examination. Images were captured with an inverted
FSX 100 microscope (Olympus Corporation). Digital images were processed with Adobe Photoshop (version 7.0, Adobe Systems, Inc.) and ImageJ software (v1.50, National Institutes of Health). 


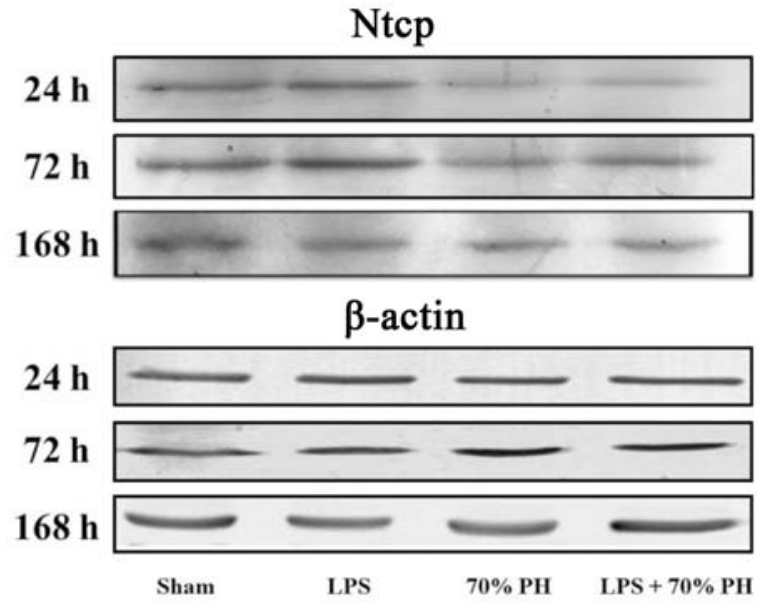

Figure 3. Western blotting for Ntcp in liver tissue membrane samples at 24 , 72 , and $168 \mathrm{~h}$ after each operation, and for $\beta$-actin; $100 \mu \mathrm{g}$ of protein was separated per lane. Ntcp, taurocholate cotransporting polypeptide; LPS, lipopolysaccharide; $\mathrm{PH}$, partial hepatectomy.

Statistical analysis. Experiments for which a statistical analysis was indicated were performed independently at least three times. Data are presented as the mean \pm standard deviation. Statistical comparisons were analyzed using SPSS software (v22.0, IBM Corp.). Differences between experimental groups were assessed for significance using two-way ANOVA with a Tukey's post-hoc test. $\mathrm{P}<0.05$ was considered to indicate a statistically significant difference.

\section{Results}

Elevated plasma bilirubin and bile acid levels in the LPS + $P H$ group. Bilirubin and bile acid levels in the plasma at $24 \mathrm{~h}$ post-operation were significantly increased in the LPS $+\mathrm{PH}$ group compared with those in the sham group. The bile acid level was significantly higher in the LPS + PH group than that in the PH group (Fig. 1). These results indicated that LPS induced cholestasis in this rat model. AST and ALT levels in the plasma at $24 \mathrm{~h}$ were significantly increased in the LPS + PH group and $\mathrm{PH}$ group, compared with those in the sham group.

Suppression and delay in DNA replication in the $L P S+P H$ group. Microarray analysis was performed to comprehensively analyze alterations in liver gene expression. Data were expressed as signal values, and changes of $>2$-fold or $<1 / 2$ from the values in the control or sham groups were considered significant. Ribonucleotide reductase regulatory subunit M2 (Rrm2), DNA topoisomerase II $\alpha$ and proliferating cell nuclear antigen (Pcna), which are markers of DNA replication (6), reached a peak level of expression after $24 \mathrm{~h}$ in the $\mathrm{PH}$ group and gradually decreased thereafter. However, in the LPS + PH group, these replication signals were low after $24 \mathrm{~h}$ and peaked after $72 \mathrm{~h}$. The values at $72 \mathrm{~h}$ were lower than those at $24 \mathrm{~h}$ in the $\mathrm{PH}$ group (Table II). These results suggested a delay and suppression in DNA replication in the LPS + PH group. No notable changes were observed in $C d 68$ or $C d 163$ expression, which are markers of Kupffer cells $(12,22)$. The chemokine Cxcl9 markedly increased in the LPS group and LPS $+\mathrm{PH}$ group, compared with that in the sham at $24 \mathrm{~h}$ (Table II). For sinusoid transporters, Ntcp (SlclOal), Oatp1(Slc2lal) and Oatp2 (Slc21a2) were reduced in the LPS $+\mathrm{PH}$ and the PH groups at $24 \mathrm{~h}$. These expression levels returned to control levels at $72 \mathrm{~h}$ in both groups. No notable changes were observed in collagen $1 \alpha 1$ or desmin, markers of hepatic stellate cells, or in cytokeratin 19 or epithelial cell adhesion molecule, markers of liver progenitor cells (23) (Table II).

To confirm these changes in gene expression, RT-qPCR was performed. Abcc2, Oatp1, and Oatp2 mRNA levels were significantly decreased at $24 \mathrm{~h}$ in the LPS $+\mathrm{PH}$ group and PH group, compared with those in the sham group. These mRNA levels except Oatp2 were not significantly different between the LPS + PH and the PH groups (Fig. 2A). The Rrm 2 mRNA levels at $24 \mathrm{~h}$ in the LPS $+\mathrm{PH}$ group were lower than those in the PH group (Fig. 2B). Rrm 2 and Pcna peaked at $24 \mathrm{~h}$ in the $\mathrm{PH}$ group, whereas at $72 \mathrm{~h}$, the levels increased in the LPS + $\mathrm{PH}$ group (Fig. 2B), confirming the results obtained by microarray analysis. $\mathrm{Cxcl} 9$ showed a significant rise after $24 \mathrm{~h}$ in the LPS and LPS + PH groups compared with the control and PH groups, respectively (Fig. 2B). These findings suggested that Cxcl9 expression was dependent on LPS treatment.

Ntcp protein levels were examined by western blotting; Ntcp expression was decreased in the PH and LPS + PH group at $24 \mathrm{~h}$ compared with the sham group (Fig. 3).

Expression of Cxcl9 in Kupfer cells activated by LPS treatment. Although $C d 68$ mRNA or $C d 163$ mRNA levels were unaltered as determined by microarray analysis (Table II), staining for CD68, a marker of Kupffer cells and macrophages (22), revealed a marked increase in CD68-positive Kupffer cells in the LPS and LPS + PH groups, compared with that in the sham and PH groups (Fig. 4A). CD163 staining, a marker for M2 macrophages and Kupffer cells (12) was positive in cells in the LPS and LPS + PH groups (Fig. 4B). These CD163-positive cells were not detected in the sham or PH groups. There were fewer CD163-positive cells than CD68-positive cells, and their cell shapes were different from each other. These results suggested that CD163-positive cells detected after LPS treatment denoted M2-type Kupffer cells (12). There were also Cxc19-positive cells in the LPS and LPS + PH groups (Fig. 4C), whereas Cxcl9-positive cells were not detected in the sham or PH groups. The number of Cxc19-positive cells was similar to that of CD163-positive cells rather than CD68-positive cells (Fig. 4D).

Expression of Ptgds2 in hepatocytes in the LPS + PH group. As Ptgds2 inhibits cell proliferation (15), Ptgds 2 staining was performed. A positive reaction was only detected in hepatocytes of the LPS + PH group, but not in other groups (Fig. 5). Kupffer cells were not stained in any groups. In the LPS $+\mathrm{PH}$ group, Ptgds 2 was markedly stained in hepatocytes at $24 \mathrm{~h}$, weakly stained at $72 \mathrm{~h}$, but not at $168 \mathrm{~h}$.

\section{Discussion}

In the rat PH model of the present study, LPS treatment induced cholestasis and delayed cell proliferation. Compared with the sham group, the expression of anion transporters involved in the uptake from the sinusoid was downregulated at $24 \mathrm{~h}$ in both the PH and the LPS + PH groups, but did not differ between the 
A
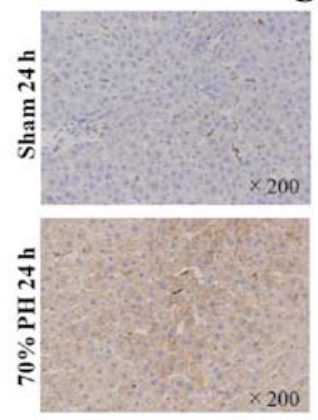

CD68
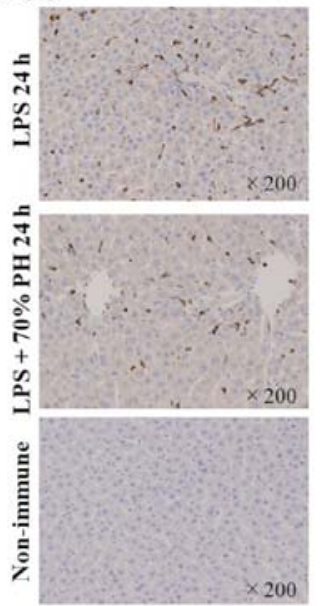

C

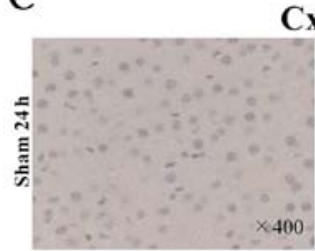

Cxcl9

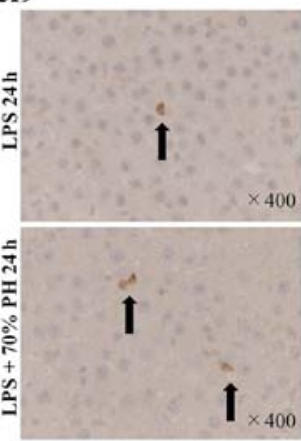

B

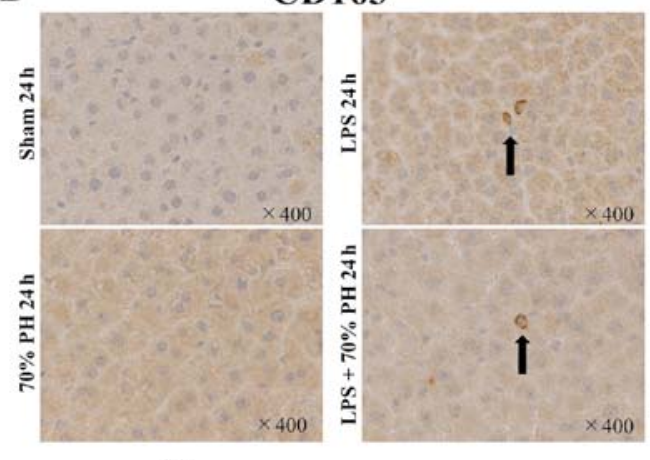

D

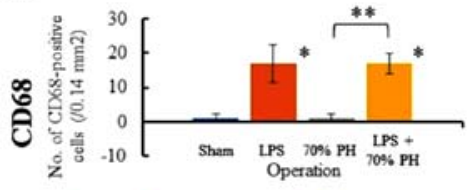

- Sham $\mid$ LPS $=70 \% \mathrm{PH}=\mathrm{LPS}+70 \% \mathrm{PH}$
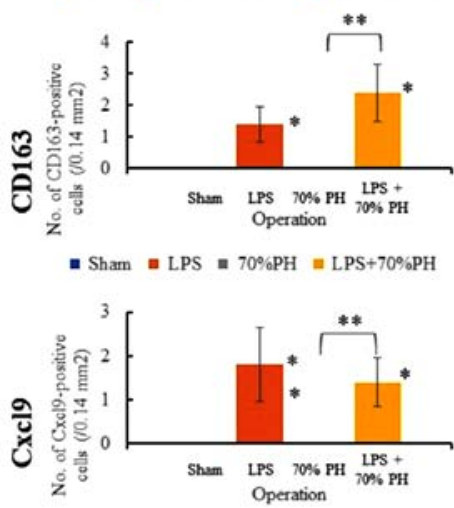

| Sham | LPS | $70 \% \mathrm{PH}=\mathrm{LPS}+70 \% \mathrm{PH}$

${ }^{*} p<0.05$ vs. sham group; ${ }^{* *} p<0.05$ LPS $+70 \%$ PH group vs. $70 \%$ PH group.

Figure 4. Immunostaining. (A) CD68, (B) CD163, and (C) Cxc19 expression in the sham, LPS, PH and LPS + PH groups at 24 h. Staining was also analyzed with non-immune $\gamma$-globulin for (A). Arrows in the panels indicated positive cells. The data presented are from a representative preparation set and are similar to the results obtained from other sets. Original magnification: (A) x200, and (B and C) x400. (D) Number of CD68-, CD163- and Cxc19-positive cells. The cells in the liver sections were from five microscope fields $\left(0.14 \mathrm{~mm}^{2}\right)$ from each rat. Data are presented as the mean \pm standard deviation from three rats. ${ }^{*} \mathrm{P}<0.05$ vs. sham group; ${ }^{* *} \mathrm{P}<0.05$ LPS $+\mathrm{PH}$ group vs. $\mathrm{PH}$ group. LPS, lipopolysaccharide; $\mathrm{PH}$, partial hepatectomy.

latter two groups. Downregulation of these anion transporters is a causative factor for cholestasis after $90 \% \mathrm{PH}(6,7,24)$. However, this was unlikely in the case of cholestasis in the LPS + PH group; suppression or delays in cell proliferation may be the responsible factor. Downregulation of marker genes of DNA replication, such as Rrm2 was determined by RT-qPCR analysis; however, delays in cell proliferation are not confirmed by protein levels, as immunohistochemistry for Pcna was not conducted. Hepatocyte proliferation is blocked by 2-acetylaminofluorene administration during PH in rats (25). In this case, biliary epithelial cells and hepatic stellate cells become progenitor cells, and these cells contribute to liver regeneration (25). In the case of LPS, activation of these cells was not detected, and microarray and RT-qPCR data suggested that hepatocyte proliferation was inhibited transiently.

Our findings revealed that LPS treatment increased the count of CD68-positive cells and CD163-positive cells. These results confirmed the activation of Kupffer cells by LPS as reported previously (26). From microarray analysis, $C d 68$ and $C d 163$ expression was determined to be unaffected by

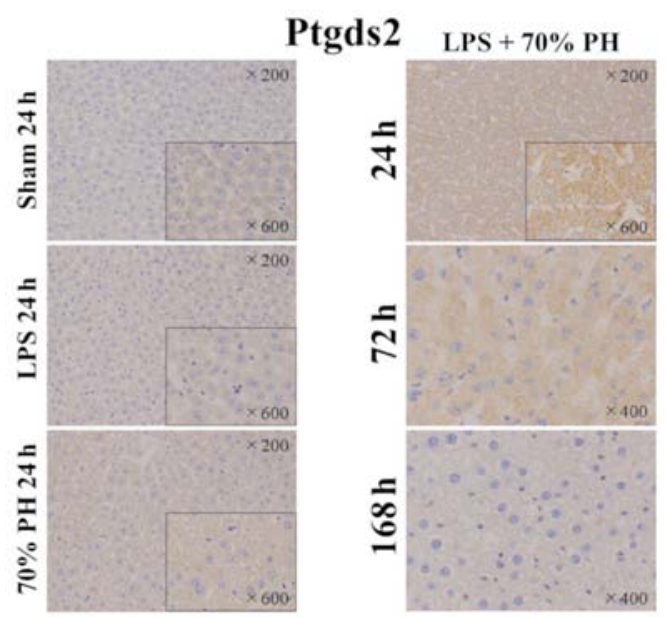

Figure 5. Immunostaining for hematopoietic Ptgds2 in the sham, LPS, PH and LPS + PH groups at $24 \mathrm{~h}$. Original magnification: $\mathrm{x} 200$; the small panels are of a higher magnification (magnification, x600) of the original panel. Immunostaining for Ptgds 2 in LPS + PH group on 72 , and $168 \mathrm{~h}$ (original magnification, $\mathrm{x} 400$ ). Ptgds2, prostaglandin $\mathrm{D}_{2}$ synthase; LPS, lipopolysaccharide; $\mathrm{PH}$, partial hepatectomy. 
LPS treatment despite increases in the number of CD68- and CD163-positive cells as detected by immunostaining. This discrepancy may reflect a difference between mRNA and protein expression; however, further investigation is required. As CD163 is a marker of M2-type macrophages $(12,22)$, CD163-positive cells may belong to M2-Kupffer cells (22). Thus, CD68-positive cells may denote M1-type macrophages or Kupffer cells (27). A marked increase in the number of CD68-positive cells by LPS treatment raises two possibilities: The proliferation of CD68-positive cells in the liver or the migration of CD68-positive cells to the liver from bone marrow $(28,29)$. The absence of alterations in $C d 68$ mRNA levels by LPS treatment suggests the latter explanation as a more likely possibility.

In the present study, $\mathrm{Cxcl} 9$ was significantly induced by LPS treatment. Immunohistochemistry suggested that $\mathrm{Cxcl} 9$ was expressed by CD163-positive cells. Double staining for Cxc19 and CD163 should be conducted to establish this possibility. Cxcl9 is a member of a family of ligands for the $\mathrm{Cxcr} 3$ receptor, which is involved in chronic inflammation and cancer (13). Cxcl9 is also a biomarker of acute cellular rejection after liver transplantation (30). Endothelial cell growth is stimulated or inhibited depending on alternatively spliced variants of Cxcr3 (31). Cxcl9 is expressed in macrophages $(32,33)$ and $\mathrm{C}-\mathrm{X}-\mathrm{C}$ motif chemokine receptor 3 (Cxcr3) promotes M2 macrophage polarization in human liver cancer (14). Prostaglandin $\mathrm{E}_{2}$ inhibits CXCR3 ligand secretion induced by interferon- $\gamma$ treatment in human breast cancer cells (34).

Ptgds2 is the hematopoietic-type Ptgds and is expressed in mast cells and macrophages (35). Ptgds2 is also expressed in skeletal muscle cells with muscular dystrophy (36). Inhibition of Ptgds2 stimulates the survival of muscle cells via the suppression of muscular cell death (37). Lymphocytes isolated from Ptgds2 knock-out mice exhibit hyperproliferation (15). The time courses of Ptgds2 staining and cell proliferation had opposite profiles in our study. Thus, Ptgds 2 was suggested to suppress hepatocyte proliferation. Ptgds2 was not detected in the LPS or PH groups, but was expressed in hepatocytes of the LPS + PH group. These results indicated that LPS and cell proliferation signals may be required for the induction of Ptgds2 expression in hepatocytes. The findings indicating that LPS alone did not alter cell proliferation suggested that a delay in cell proliferation in the LPS + PH group may not be due to the direct effects of LPS on hepatocytes, but due to Kupffer cells activated by LPS. Cxc19 may be a candidate signaling molecule released from Kupffer cells for Ptgds2 expression in hepatocytes; however, because Cxc19 was produced by LPS alone, Cxc19 may not be sufficient for Ptgds2 expression. Ptgds2 may be a target to prevent a delay in cell proliferation after PH induced by LPS or bacterial infections.

\section{Acknowledgements}

The authors would like to thank Ms. Yukie Fujita and Ms. Sayumi Kubo (Department of Pathology and Bioscience, Hirosaki University Graduate School of Medicine) for their technical assistance in immunostaining, and Ms. Ryoko Seito, Mr. Hitoshi Kudo and Ms. Ikumi Shirahama (Institute for
Animal Experimentation, Hirosaki University Graduate School of Medicine) for their technical assistance for animal treatment.

\section{Funding}

The present study was partly supported by the Japan Society for the Promotion of Science KAKENHI (grant no. 15K20845; Grant-in-Aid for Young Scientists B). No additional external funding was received for this study.

\section{Availability of data and materials}

All data generated or analyzed during the present study are included in this published article.

\section{Authors' contributions}

YW, NK and ST conceived the idea and design of the present study. YW, NK, TY and TS performed the animal experiments. YW, KH and ST wrote the manuscript. YW, NK and ST discussed the results and contributed to the final version of the manuscript. KH performed the statistical analyses. All authors approved the final version of the manuscript to be published.

\section{Ethics approval and consent to participate}

All animal experiments were conducted strictly according to ethical standards and approved by the Animal Ethical Committee of Hirosaki University Graduate School of Medicine (approval ID: M15041).

\section{Patient consent for publication}

Not applicable.

\section{Competing interests}

The authors declare that they have no competing interests.

\section{References}

1. Preziosi ME and Monga SP: Update on the mechanisms of liver regeneration. Semin Liver Dis 37: 141-151, 2017.

2. Hu J, Srivastava K, Wieland M, Runge A, Mogler C, Besemfelder E, Terhardt D, Vogel MJ, Cao L, Korn C, et al: Endothelial cell-derived angiopoietin-2 controls liver regeneration as a spatiotemporal rheostat. Science 343: 416-419, 2014.

3. Marrone G, Shah VH and Bracia-Sancho J: Sinusoidal communication in liver fibrosis and regeneration. J Hepatol 65: 608-617, 2016.

4. Mabuchi A, Mullaney I, Sheard PW, Hessian PA, Mallard BL, Tawadrous MN, Zimmermann A, Senoo $\mathrm{H}$ and Wheatley AM: Role of hepatic stellate cell/hepatocyte interaction and activation of hepatic stellate cells in the early phase of liver regeneration in the rat. J Hepatol 40: 910-916, 2004.

5. DeLeve LD: Liver sinusoidal endothelial cells and liver regeneration. J Clin Invest 123: 1861-1866, 2013.

6. Miura T, Kimura N, Yamada T, Shimizu T, Nanashima N, Yamana D, Hakamada K and Tsuchida S: Sustained repression and translocation of Ntcp and expression of Mrp4 for cholestasis after rat 90\% partial hepatectomy. J Hepatol 55: 407-414, 2011.

7. Cuperus FJ, Claudel T, Gautherot J, Halilbasic E and Trauner M: The role of canalicular ABC transporters in cholestasis. Drug Metab Dispos 42: 546-560, 2014.

8. Abad CL, Lahr BD and Razonable RR: Epidemiology and risk factors for infection after living donor liver transplantation. Liver Transpl 23: 465-477, 2017. 
9. Jörger AK, Liu L, Fehlner K, Weisser T, Cheng Z, Lu M, Höchst B, Bolzer A, Wang B, Hartmann D, et al: Impact of NKT cells and LFA-1 on liver regeneration under subseptic conditions. PLoS One 11: e0168001, 2016.

10. Liu H, Liao R, He K, Zhu X, Li P and Gong J: The SMAC mimetic birinapant attenuates lipopolysaccharide-induced liver injury by inhibiting the tumor necrosis factor receptor-associated factor 3 degradation in Kupffer cells. Immunol Lett 185: 79-83, 2017.

11. Meijer C, Wiezer MJ, Diehl AM, Schouten HJ, Schouten HJ, Meijer S, van Rooijen N, van Lambalgen AA, Dijkstra CD and van Leeuwen PA: Kupffer cell depletion by Cl2MDP-liposomes alters hepatic cytokine expression and delays liver regeneration after partial hepatectomy. Liver 20: 66-77, 2000.

12. Edin S, Wikberg ML, Dahlin AM, Rutegard J, Oberg A, Oldenborg PA and Palmqvist R: The distribution of macrophages with a M1 or M2 phenotype in relation to prognosis and the molecular characteristics of colorectal cancer. PLoS One 7 e47045, 2012.

13. Billottet C, Quemener C and Bikfalvi A: CXCR3, a double-edged sword in tumor progression and angiogenesis. Biochim Biophys Acta 1836: 287-295, 2013

14. Liu RX, Wei Y,Zeng QH, Chan KW, Xiao X, Zhao XY, Chen MM, Ouyang FZ, Chen DP, Zheng L, et al: Chemokine (C-X-C motif) receptor 3-positive B cells link interleukin-17 inflammation to protumorigenic macrophage polarization in human hepatocellular carcinoma. Hepatology 62: 1779-1790, 2015.

15. Trivedi SG, Newson J, Rajakariar R, Jacques TS, Hannon R, Kanaoka Y, Eguchi N, Colville-Nash P and Gilroy DW: Essential role for hematopoietic prostaglandin D2 synthase in the control of delayed type hypersensitivity. Proc Natl Acad Sci USA 103 5179-5184, 2006.

16. National Research Council (US) Committee for the Update of the Guide for the Care and Use of Laboratory Animals: Guide for the Care and Use of Laboratory Animals. 8th edition, National Academies Press, Washington, DC, 2011.

17. Livak KJ and Schmittgen TD: Analysis of relative gene expression data using real-time quantitative PCR and the 2(-Delta Delta C(T)) method. Methods 25: 402-408, 2001.

18. Gant TW, Silverman JA, Bisgaard HC, Burt RK, Marino PA and Thorgeirsson SS: Regulation of 2-acetylaminofluorene- and 3-methylcholanthrene-mediated induction of multidrug resistance and cytochrome P450IA gene family expression in primary hepatocyte cultures and rat liver. Mol Carcinog 4: 499-509, 1991.

19. Bradford MM: A rapid and sensitive method for the quantitation of microgram quantities of protein utilizing the principle of protein-dye binding. Anal Biochem 72: 248-254, 1976.

20. Hsu SM, Raine L and Fanger H: Use of avidin-biotin-peroxidase complex $(A B C)$ in immunoperoxidase techniques: A comparison between $A B C$ and unlabeled antibody (PAP) procedures. J Histochem Cytochem 29: 577-580, 1981.

21. Hebert GA: Ammonium sulfate fractionation of sera: Mouse, hamster, guinea pig, monkey, chimpanzee, swine, chicken, and cattle. Appl Microbiol 27: 389-393, 1974.

22. Dixon LJ, Barnes M, Tang H, Pritchard MT and Nagy LE: Kupffer cells in the liver. Compr Physiol 3: 785-797, 2013.

23. Yovchev MI, Grozdanov PN, Zhou H, Racherla H, Guha C and Dabeva MD: Identification of adult hepatic progenitor cells capable of repopulating injured rat liver. Hepatology 47: 636-647, 2008.

24. Chang TH, Hakamada K, Toyoki Y, Tsuchida S and Sasaki M: Expression of MRP2 and MRP3 during liver regeneration after 90\% partial hepatectomy in rats. Transplantation 77: 22-27, 2004.
25. Kordes C, Sawitza I, Götze S, Herebian D and Häussinger D: Hepatic stellate cells contribute to progenitor cells and liver regeneration. J Clin Invest 124: 5503-5515, 2014.

26. Suzuki S, Nakamura S, Serizawa A, Sakaguchi T, Konno H, Muro H, Kosugi I and Baba S: Role of Kupffer cells and the spleen in modulation of endotoxin-induced liver injury after partial hepatectomy. Hepatology 24: 219-225, 1996.

27. Tacke F and Zimmermann HW: Macrophage heterogeneity in liver injury and fibrosis. J Hepatol 60: 1090-1096, 2014.

28. Aldeguer X, Debonera F, Shaked A, Krasinkas AM, Gelman AE, Que X, Zamir GA, Hiroyasu S, Kovalovich KK, Taub R and Olthoff KM: Interleukin- 6 from intrahepatic cells of bone marrow origin is required for normal murine liver regeneration. Hepatology 35: 40-48, 2002.

29. Nishiyama K, Nakashima H, Ikarashi M, Kinoshita M, Nakashima M, Aosasa S, Seki S and Yamamoto J: Mouse $\mathrm{CD} 11 \mathrm{~b}+\mathrm{Kupffer}$ cells recruited from bone marrow accelerate liver regeneration after partial hepatectomy. PLoS One 10: e0136774, 2015.

30. Asaoka T, Marubashi S, Kobayashi S, Hama N, Eguchi H, Takeda Y, Tanemura M, Wada H, Takemasa I, Takahashi H, et al: Intragraft transcriptome level of CXCL9 as biomarker of acute cellular rejection after liver transplantation. J Surg Res 178: 1003-1014, 2012

31. Lasagni L, Francalanci M, Annunziato F, Lazzeri E, Giannini S, Cosmi L, Sagrinati C, Mazzinghi B, Orlando C, Maggi E, et al: An alternatively spliced variant of CXCR3 mediates the inhibition of endothelial cell growth induced by IP-10, Mig, and I-TAC, and acts as functional receptor for platelet factor 4. J Exp Med 197: 1537-1549, 2003.

32. Farber JM: A macrophage mRNA selectively induced by gamma-interferon encodes a member of the platelet factor 4 family of cytokines. Proc Natl Acad Sci USA 87: 5238-5242, 1990.

33. Metzemaekers M, Vanheule V, Janssens R, Struyf S and Proost P: Overview of the mechanisms that may contribute to the non-redundant activities of interferon-inducible CXC chemokine receptor 3 ligands. Front Immunol 8: 1970, 2018.

34. Bronger H, Kraeft S, Schwarz-Boeger U, Cerny C, Stöckel A, Avril S, Kiechle M and Schmitt M: Modulation of CXCR3 ligand secretion by prostaglandin E2 and cyclooxygenase inhibitors in human breast cancer. Breast Cancer Res 14: R30, 2012.

35. Gandhi UH, Kaushal N, Ravindra KC, Hegde S, Nelson SM, Narayan V, Vunta H, Paulson RF and Prabhu KS: Selenoprotein-dependent up-regulation of hematopoietic prostaglandin D2 synthase in macrophages is mediated through the activation of peroxisome proliferator-activated receptor (PPAR) gamma. J Biol Chem 286: 27471-27482, 2011.

36. Okinaga T, Mohri I, Fujimura H, Imai K, Ono J, Urade Y and Taniike M: Induction of hematopoietic prostaglandin D synthase in hyalinated necrotic muscle fibers: Its implication in grouped necrosis. Acta Neuropathol 104: 377-384, 2002.

37. Mohri I, Aritake K, Taniguchi H, Sato Y, Kamauchi S, Nagata N, Maruyama T, Taniike M and Urade Y: Inhibition of prostaglandin D synthase suppresses muscular necrosis. Am J Pathol 174: 1735-1744, 2009.

(7) $\Theta$ This work is licensed under a Creative Commons Attribution-NonCommercial-NoDerivatives 4.0 International (CC BY-NC-ND 4.0) License. 